\title{
Desempenho Financeiro Das Empresas Brasileiras De Ti: Uma Aplicação De Análise Fatorial
}

\section{Financial Performance Of It Brazilians Companies: An Application Of Factor Analysis}

\author{
Mário Augusto Parente Monteiro ${ }^{1}$, Marcus Vinicius de Oliveira Brasil², José Leonel Paareja Credídio ${ }^{3}$, \\ Danival Sousa Cavalcante ${ }^{2}$, Milton Jarbas Rodrigues ${ }^{2}$
}

\author{
${ }^{1}$ Universidade de Fortaleza, UNIFOR, Brasil. ${ }^{2}$ Universidade Federal do Cariri, UFCA, Brasil. ${ }^{3}$ Faculdade \\ Ateneu, FATE, Brasil. \\ Correspondência: Danival Sousa Cavalcante. Av. Tenente Raimundo Rocha, s/n, Bairro Cidade Universitária, \\ CEP 63048-080, Juazeiro do Norte, CE. Telefone: +55 (88) 3221-9200. E-mail: danivalsc@ @otmail.com.
}

Recebido: 20 de janeiro de 2017 Aceito: 14 de novembro de 2017 Publicado: 31 de maio de 2018

DOI: http://dx.doi.org/10.21714/1679-18272017v15n2.p530-545

\begin{abstract}
Resumo
O estudo busca encontrar resposta para como avaliar de forma objetiva a qualidade da gestão de um empreendimento e, por extensão, de seus gestores. A resposta passa pela avaliação do desempenho financeiro das empresas pesquisadas. Com o fim de verificar os efeitos da crise financeira de 2008 sobre o desempenho do setor de TI, utiliza-se dados de dois períodos distintos, 2007 e 2009. Os dados obtidos da análise fatorial evidenciam que o desempenho financeiro das empresas brasileiras atuantes no setor de TI é explicado pelas variáveis associadas ao resultado operacional, nos dois períodos considerados (antes e após da crise de 2008). As variáveis relacionadas à estrutura patrimonial assumem maior relevância no período posterior a 2008, na medida em que é calculado um fator atribuível a elas. É possível, portanto, observar que a crise financeira de 2008 não produziu significativas alterações na composição do desempenho financeiro das empresas de TI, ainda que a maior relevância da estrutura patrimonial comprove que, diante das restrições existentes no mercado de crédito, tenha tornado o nível de endividamento (medida representativa da estrutura de capital) um diferencial de performance para empresas avaliadas.
\end{abstract}

Palavras-chave: Tecnologia da Informação. Desempenho Financeiro. Análise Fatorial.

\begin{abstract}
The study seeks to find an answer to how to evaluate objectively the quality of management of an enterprise and, by extension, of its managers. The answer involves the evaluation of the financial performance of the companies surveyed. In order to verify the effects of the financial crisis on IT industry performance at 2008, about IT industry performance, it used data from two different periods, 2007 and 2009. The data obtained from factor analysis show that the financial performance of brazilian companies working in the IT industry it is explained by variables associated with operating results, in both periods considered (Before and after the 2008 crisis). The variables related to capital structure assumes greater relevance in the period after to 2008 , just right which is a calculated factor attributable to them. It is therefore possible to note that the financial crisis of 2008 produced no significant changes on composition of the financial performance in IT companies, although the most relevant equity structure proves debt (representative measure of capital structure) a differential performance for companies evaluated.
\end{abstract}

Keywords: Information technology. Financial performance. Factor analysis.

Esta obra está licenciada sob uma Licença Creative Commons Attribution 3.0.

\section{Introdução}

A atividade empresarial compreende um contínuo processo de tomada de decisões relativas às suas dimensões 
básicas, ou seja, operacional e financeira. A qualidade das decisões tomadas pelos gestores é determinante do grau de sucesso do empreendimento realizado. Dessa forma, cumpre aos administradores acompanhar e avaliar a qualidade de suas decisões, a fim de reforçar aquelas acertadas e, eventualmente, corrigir aquelas que demonstraram equivocadas. A questão que se põe diz respeito a como avaliar de forma objetiva a qualidade da gestão de um empreendimento e, por extensão, de seus gestores. A resposta para tal questão passa pela avaliação dos resultados, expressos em termos financeiros, da empresa, ou seja, pela avaliação de seu desempenho financeiro.

A avaliação de desempenho financeiro de uma empresa, bem como de sua solidez econômica, envolve a utilização de métodos e técnicas variadas, todas elas recorrendo, necessariamente, às informações constantes dos demonstrativos contábil-financeiros de elaboração obrigatória (notadamente, balanço patrimonial e demonstração do resultado do exercício), bem como, eventualmente, a outras informações provenientes do mercado, tais como tendências econômicas e dados relativos ao setor de atividade econômica no qual a organização sob análise está inserida. Nesse sentido, afirma Ross et al. (2008), a principal razão de examinar informações contábeis é porque não possuímos e não podemos esperar obter as informações de mercado necessárias de uma maneira razoável.

Com base nos dados constantes das demonstrações contábeis, são construídos índices financeiros, cuja interpretação constitui importante método para mensuração e avaliação do desempenho empresarial. Esse entendimento é reforçado por Catelli (2001), para quem o ato de avaliar, em um sentido genérico, equivale ao exercício da análise e do julgamento de qualquer situação e a avaliação implica consequências positivas ou negativas. Resta evidente, portanto, que a avaliação financeira torna-se instrumento de verificação do alcance dos objetivos ou expectativas estabelecidas para a empresa.

A relevância da avaliação do desempenho financeiro é aumentada em momentos de crise econômica, tal como aquela com "epicentro" em 2008, em razão, por exemplo, da menor disponibilidade de capitais para o financiamento empresarial, do maior nível risco no ambiente econômico no qual operam as empresas e, por consequência, da maior seletividade dos investidores, que impõem requisitos mais elevados de desempenho às empresas. A crise, cujo início foi observado em 2007 nos Estados Unidos em decorrência de problemas no pagamento de hipotecas, contaminou o sistema mundial por meio do mercado de crédito. No Brasil, ainda que atingido diretamente pelos problemas financeiros observados em países desenvolvidos, vários setores sofreram com a contração de crédito e, em seguida, pela queda das exportações e da demanda interna, que foi o "motor" do crescimento do país nos anos anteriores. Os setores que mais sofreram com a queda da demanda, tanto no Brasil como no resto do mundo, foram o automotivo, o de bens de consumo duráveis (entre eles, os bens eletroeletrônicos) e o de bens de capital, na medida em vendem produtos que dependem diretamente de financiamento, tornado escasso pela crise. A realidade descrita é particularmente aplicável às empresas atuantes no setor dedicado à tecnologia de informação - TI.

Cumpre destacar que nas últimas décadas, a economia mundial experimentou profundas mudanças. Os modelos de produção e acumulação, até então vigentes, foram transformados pelo rápido desenvolvimento das tecnologias intensivas em informação, flexíveis e computadorizadas, as quais implicaram o estabelecimento da denominada Sociedade da Informação. Essas mudanças representaram uma revolução tecnológica, cujo elemento central é formado por um conjunto de tecnologias, baseadas na microeletrônica, nas telecomunicações e na informática, reunidas sob a denominação de Tecnologia de Informação - TI.

Dessa forma, o setor de TI pode ser entendido como a combinação de atividades industriais, comerciais e de serviços, voltadas à captação, transmissão e disseminação por meio eletrônico de dados e informação, bem como à comercialização de equipamentos e produtos intrinsecamente vinculados a esse processo.

No Brasil, de acordo com dados do IBGE (2009), o total do setor de TI era formado, no ano de 2006, por 65.754 empresas que ocupavam 673.024 pessoas. Tendo participação no valor adicionado/valor da transformação industrial gerado pelo total da economia brasileira da ordem aproximada de $8,5 \%$, esse setor caracteriza-se pela existência de grandes empresas, concentradoras tanto de pessoal ocupado, quanto de produção, ao lado de um grande número de pequenas empresas (em torno de $85 \%$ do total de empresas do setor). A realidade descrita é confirmada por dados do IBGE (2009) segundo os quais 48,2\% das pessoas ocupadas no setor de TI em 2006 trabalhavam em empresas com 250 ou mais pessoas, bem como $76,1 \%$ do valor adicionado/valor da transformação industrial por tal setor correspondiam à contribuição das grandes empresas. As 200 maiores empresas de tecnologia do Brasil cresceram 10\% em 2009, faturando, em conjunto, 149 bilhões de dólares nesse ano.

Considerando a contribuição do setor de TI para a economia brasileira, a pesquisa volta-se para a identificação 
dos fatores explicativos do desempenho financeiro das empresas desse setor a partir da realização de análise multivariada das informações obtidas e índices financeiros construídos a partir dos demonstrativos contábeis elaborados por tais empresas. Ademais, a fim de verificar os efeitos da crise financeira de 2008 sobre o desempenho dessas empresas, serão utilizados dados referentes a dois períodos distintos, respectivamente, o ano 2007 (anterior à crise) e o ano 2009 (posterior à crise). Os resultados encontrados serão comparados com os resultados produzidos por outros estudos referentes ao desempenho financeiro de empresas (identificados a partir de sucinta revisão da literatura existente acerca do tema), ainda que de outros setores econômicos, a fim de identificar padrões explicativos para tal desempenho.

\section{Referencial Teórico}

\subsection{Análise Financeira}

A mensuração e a posterior análise do desempenho constituem objeto de pesquisa em diferentes campos de conhecimento. Especificamente, parcela significativa dos estudos realizados é orientada para construção e/ou identificação de indicadores de desempenho que atendam determinados requisitos, tais como objetividade, mensurabilidade, compreensibilidade, comparabilidade e economicidade.

No campo empresarial, a avaliação do desempenho possibilita uma reflexão sobre a estratégia e sobre os planos da empresa, identificando suas limitações e suas potencialidades. A partir dessa reflexão é possível a tomada de decisões destinadas a aproveitar as oportunidades existentes, bem como a corrigir os resultados de ações passadas menos acertadas.

De acordo com Del Corso et al. (2009), há diversos métodos e técnicas para a avaliação de desempenho financeiro de uma empresa, assim como para a verificação de sua solidez financeira. Para os autores, todas as técnicas passam pela verificação dos demonstrativos contábil-financeiros disponíveis, além de outras informações provenientes do mercado, como tendências econômicas, dados pertinentes ao segmento econômico que a organização está inserida, entre outras. Os referidos autores reforçam a essencialidade dos dados e informações providas pela contabilidade para a análise financeira de empresas.

Assim, dada a origem contábil das informações requeridas para a análise financeira, é necessário o entendimento de alguns conceitos contábeis básicos, notadamente aqueles referentes à estruturação das diferentes demonstrações elaboradas. Especificamente, cumpre destacar o entendimento da diferença existente entre contas patrimoniais e contas de resultado, na medida em que a utilização, na análise financeira, das primeiras ou das últimas resulta em diferentes diagnósticos.

Com base nas demonstrações contábeis, são calculados índices econômico-financeiros, os quais se constituem em uma das ferramentas mais utilizadas na análise financeira de empresas. O uso de índices permite dimensionar aspectos específicos do desempenho empresarial em um determinado período, possibilitando, ademais, a consolidação de grande quantidade de informações sobre uma empresa, bem como a projeção de sua performance futura.

De acordo com Matarazzo (2003), os índices formam a técnica de análise mais empregada. Geralmente, na prática, ou mesmo em livros, confunde-se análise de balanços com extração de índices. A principal característica dos índices é fornecer ampla visão da situação econômica ou financeira da empresa. Para Marion (2009), a análise financeira de uma empresa é facilitada pelo uso de indicadores calculados.

Portanto, os índices possibilitam a avaliação do desempenho da empresa em um período, por meio da comparação com o índice de outras empresas, com índices-padrão e/ou com seus correspondentes valores ao longo de vários exercícios. Acerca do emprego de índices financeiros Matarazzo (2003) adverte que o importante não é o simples cálculo de grande número de índices, mas de um conjunto de índices que permita identificar a situação real da empresa, segundo o grau de profundidade desejada de cada análise.

Dada a existência de uma grande diversidade de índices, quocientes e múltiplos, aplicáveis à análise financeira, é recomendável que tais índices sejam dispostos em grupos ou modelos específicos voltados para à análise da performance da empresa sob diferentes ângulos. Para Gitman (2004) os índices financeiros podem ser separados em quatro grupos ou categorias básicas: índices de liquidez, índices de atividade, índices de endividamento e índices de lucratividade. A despeito dessa classificação sugerida por Gitman, diferentes autores estabelecem outras categorizações para os índices financeiros, de acordo com os diferentes objetivos e graus de profundidade com que se pretende avaliar o desempenho financeiro da(s) empresa(s).

Por exemplo, segundo Assaf Neto (2003), os índices devem ser agrupados em tornos das principais áreas de análise da performance empresarial, a saber, endividamento, liquidez e rentabilidade. Por sua vez, Matarazzo 
(2003) argumenta que os grupos de indicadores mais utilizados na avaliação de desempenho das empresas são os seguintes: estrutura de capitais, liquidez e rentabilidade.

Com base nas diferentes classificações propostas para os índices financeiros, é possível observar a existência de três grupos principais, que abrigam aqueles índices mais utilizados na avaliação do desempenho empresarial: estrutura, liquidez e rentabilidade.

Tabela 1: Índices Financeiros - Principais Tipos e Composição

\begin{tabular}{|c|c|}
\hline GRUPO/INDICE & COMPOSIÇAO \\
\hline \multicolumn{2}{|l|}{ ESTRUTURA } \\
\hline 1. ALAVANCAGEM: & Ativo Total / Patrimônio Líquido \\
\hline 2. RELAÇÃO CAPITAIS DE TERCEIROS/CAPITAIS PRÓPRIOS: & Passivo Total / Patrimônio Líquido \\
\hline 3. COMPOSIÇÃO DO ENDIVIDAMENTO: & Passivo Total / Ativo Total \\
\hline \multicolumn{2}{|l|}{ LIQUIDEZ } \\
\hline 1. LIQUIDEZ GERAL: & Ativo Total / Passivo Total \\
\hline 2. LIQUIDEZ CORRENTE: & Ativo Circulante / Passivo Circulante \\
\hline 3. LIQUIDEZ IMEDIATA: & Caixa / Passivo Circulante \\
\hline \multicolumn{2}{|l|}{ RENTABILIDADE } \\
\hline 1. RETORNO SOBRE ATIVO TOTAL (ROA): & Resultado Operacional Líquido (EBIT)/Ativo Total \\
\hline 2. RETORNO SOBRE INVESTIMENTO (ROI): & Resultado Operacional Líquido (EBIT)/investimento Total \\
\hline 3. RETORNO S/CAPITAL PRÓPRIO (ROE): & Lucro Líquido / Patrimônio Líquido \\
\hline 4. MARGEM OPERACIONAL: & Resultado Operacional Líquido (EBIT)/ Vendas Líquidas \\
\hline 5. MARGEM LÍQUIDA: & Lucro Líquido / Vendas Líquidas \\
\hline
\end{tabular}

Fontes: Elaborado pelos autores (2015)

Os índices de estrutura são utilizados para auferir a composição das fontes passivas de recursos de uma empresa, evidenciando, por exemplo, a proporção de recursos de terceiros em relação ao capital próprio e o grau de comprometimento financeiro da empresa perante seus credores. Os índices de liquidez explicitam a capacidade financeira da empresa para honrar os compromissos assumidos perante seus credores. Por fim, os índices de rentabilidade, também denominados de índices de lucratividade, indicam o retorno proporcionado pelo empreendimento. A Tabela 1 sumariza os principais índices integrantes de cada grupo, explicitando, ademais, sua composição.

\subsection{Análise Fatorial}

Ante o exposto, resta evidente que a avaliação do desempenho financeiro de em uma empresa pressupõe a definição prévia de quantos e quais índices serão utilizados, bem como estabelecer o propósito e a importância relativa de cada um deles. Nesse contexto, as técnicas de análise multivariada oferecem os meios para a identificação dos índices com maior poder de explicação do desempenho empresarial, possibilitando, dessa forma, a redução de sua quantidade para fins de análise financeira.

As técnicas multivariadas têm entre seus objetivos o aumento da habilidade explanatória do pesquisador por meio de uma maior eficiência estatística. Essas técnicas de análise são úteis para explicitar padrões no comportamento de duas ou mais variáveis, bem como para testar modelos alternativos de associação entre essas variáveis. A análise de dados associados implica respostas às questões sobre: identificação da natureza e determinação do grau de associação entre um conjunto de variáveis dependentes e um conjunto de variáveis independentes; estabelecimento de uma função que permita estimar os valores das variáveis dependentes a partir das variáveis independentes, o chamado problema da regressão; e mensuração do grau de significância estatística associada aos itens anteriores.

A análise fatorial exploratória é descrita por Hair et al. (2009) como sendo um nome genérico atribuído a uma classe de métodos estatísticos multivariados, cuja finalidade consiste em estabelecer a estrutura subjacente de uma matriz de dados. Ademais, complementam os autores, consiste em uma técnica de interdependência na qual todas as variáveis são simultaneamente consideradas, todas relacionadas entre si, empregando ainda o conceito da variável estatística, a composição linear de variáveis.

Se na análise de variância, na regressão múltipla e na análise discriminante, uma variável é suposta dependente enquanto as demais são consideradas independentes, a análise fatorial caracteriza-se por não fazer tal distinção, na medida em que é uma técnica de interdependência.

No âmbito da análise fatorial, busca-se identificar possíveis associações entre as variáveis observadas, a fim de se estabelecer a existência de um fator comum entre elas. Os fatores resultantes reúnem variáveis conforme suas correlações, ou seja, variáveis reunidas sob um determinado fator devem ser altamente correlacionadas entre si e 
fracamente correlacionadas com as variáveis integrantes de outro fator. Portanto, é possível afirmar que a análise fatorial tem como objetivo a identificação de fatores subjacentes às variáveis observadas, de modo a facilitar a interpretação dos dados e informações levantadas, por meio da consideração de um número de fatores menor que o número original de variáveis.

Segundo Malhotra (2001), o emprego da análise fatorial justifica-se nas seguintes situações: identificação das dimensões latentes ou fatores que expliquem as correlações entre um conjunto de variáveis; identificação de um conjunto novo, menor, de variáveis não correlacionadas para substituir o conjunto de variáveis correlacionadas na análise multivariada subsequente (regressão ou análise discriminante); e identificação, em um conjunto maior, de um conjunto menor de variáveis que se destacam para uso em uma análise multivariada subsequente.

Cabe destacar que a análise fatorial contempla duas abordagens básicas diferentes para a determinação dos coeficientes associados aos fatores: a análise de componentes principais e a análise fatorial comum. A análise das componentes principais é recomendada em situações nas quais busca-se "determinar o número mínimo de fatores que respondem pela máxima variância nos dados" Malhotra (2001). Por outro lado, para o mencionado autor, a análise fatorial comum é utilizada quando, além da identificação das dimensões subjacentes, a variância comum é o elemento de interesse.

A análise fatorial é constituída basicamente por quatro etapas: cálculo da matriz de correlação das variáveis em estudo para a verificação do grau de associação entre as variáveis, duas a duas. Nesta etapa, é verificada a adequação da aplicação da AF; Extração dos fatores mais significativos que representarão os dados, por meio do método mais adequado. Sabe-se quão bem o modelo representa os dados; aplicação de rotação, nos fatores, para facilitar o entendimento deles; e geração dos scores fatoriais para utilização em outras análises.

O emprego da análise fatorial para avaliação e seleção de índices financeiros encontra-se consagrado em diversos estudos anteriores sobre performance de organizações em diferentes setores de atividade econômica. Como exemplo, Bezerra e Corrar (2006) fazem uso da técnica de análise fatorial exploratória para seleção dos principais indicadores a serem empregados na avaliação do desempenho financeiro de empresas seguradoras. Procedimento semelhante foi utilizado por Carvalho e Bialoskorski (2007) na análise dos indicadores contábeis que mais influenciavam o desempenho financeiro de cooperativas agropecuárias no Estado de São Paulo. Belfiore, Fávero e de Ângelo (2006) fizeram uso da análise fatorial para identificar padrões operacionais e financeiros em empresas de logística no Brasil. A análise fatorial também foi empregada por Silva (2009) em pesquisa voltada para elaboração de metodologia destinada a reduzir o grau de subjetividade na escolha dos índices financeiros aplicáveis a avaliação de empresas do setor de seguros, além de permitir a análise simultânea do comportamento de vários indicadores. Backes et al. (2009) utilizam análise fatorial com o propósito de identificar os índices financeiros de maior significância para explicar o desempenho financeiro de empresas do setor alimentício listadas na Bolsa de Valores de São Paulo. A fim de realizar comparação acerca da performance financeira de empresas europeias com atuação no setor de tecnologia, Laitinen (2002) igualmente recorreu à análise fatorial, identificando os fatores explicativos da referida performance.

Os diversos estudos mencionados reforçam a validade do emprego da análise fatorial como ferramenta de avaliação de um conjunto de variáveis (saldos contábeis, índices financeiros e dados operacionais), com o propósito de estabelecer sua significância para a explicação do desempenho financeiro de organizações empresariais.

\subsection{Pesquisas Similares}

A utilização de técnicas de análise multivariadas em pesquisas relacionadas ao desempenho financeiro de empresas, como destacado anteriormente, não constitui novidade. Nota-se, nesse sentido, um número crescente de artigos que, fazendo uso da análise fatorial, buscam identificar elementos que melhor representem o desempenho financeiro empresarial. A seguir, são apresentados de forma sintética os objetivos e os resultados de 7 (sete) estudos realizados com o propósito mencionado. Cabe salientar que os estudos referidos não são apresentados de forma cronologicamente ordenada.

O trabalho realizado por Carvalho e Bialoskorski (2007) teve por objetivo identificar, através da análise fatorial, os indicadores contábeis mais significativos na avaliação e acompanhamento do desempenho de cooperativas agropecuárias em operação no Estado de São Paulo. Considerando dados relativos a 91 cooperativas, foram inicialmente calculados 15 índices associados a diferentes aspectos do desempenho financeiro das cooperativas pesquisadas. Tais índices são representativos de liquidez (Liquidez Corrente, Liquidez Seca e Liquidez Geral), de prazos médios da atividade (Rotação dos Estoques, Giro do Ativo Operacional e Giro do Ativo Total), de estrutura (Capital de Terceiros / Ativo Total, Grau de Endividamento, relação Capital de Terceiros / Capital 
Próprio e Quociente de Imobilização) e de rentabilidade (Margem Bruta, Margem Operacional, Margem Líquida, Quociente de Retorno sobre o Investimento e Quociente de Retorno do Patrimônio Líquido). Como resultado da análise fatorial realizada foram obtidos 3 fatores, envolvendo 10 dos índices inicialmente calculados): (i) o primeiro fator, composto pelos indicadores Liquidez Corrente, Liquidez Geral, Liquidez Seca e Margem Bruta, evidencia a situação financeira da cooperativa em termos de sua capacidade de pagamentos das obrigações correntes; (ii) o segundo fator é composto pelos indicadores Margem Líquida, Margem Operacional, Relação Capital de Terceiros / Capital Próprio e Quociente de Retorno Sobre o Patrimônio Líquido, estando, pois, associado à rentabilidade; e (iii) o último fator, relacionado à estrutura patrimonial das empresas analisadas, é integrado pelos indicadores Capital de Terceiros/Ativo Total e Endividamento. Em conjunto, os 3 fatores estabelecidos explicam $87,9 \%$ da variação observada.

Com o propósito de identificar padrões operacionais e financeiros em empresas brasileiras do setor de logística, Belfiore, Fávero e de Ângelo (2006) realizaram análise fatorial a partir de dados referentes às 21 maiores empresas em atuação no setor. Considerando inicialmente 9 variáveis distintas (Receita Líquida, Número de Funcionários, Lucro Líquido, Ativo Total, EBITDA, Endividamento, Capital de Giro e Patrimônio Líquido). A análise fatorial realizada resultou em 2 fatores, que explicam $97 \%$ da associação total entre os dados, sendo primeiro fator composto por todas as variáveis inicialmente consideradas menos a variável "número de funcionários" e o segundo fator formado exclusivamente por essa última variável.

Bezerra e Corrar (2006) empregaram a técnica de análise fatorial exploratória para seleção dos principais indicadores a serem empregados na avaliação do desempenho financeiro de empresas seguradoras. Com base em dados relativos a 15 indicadores financeiros (representativos de liquidez, de rentabilidade, de estrutura patrimonial e de alavancagem) concernentes a 107 empresas atuantes no setor de seguros, a análise fatorial chegou a 3 fatores, abrangendo 9 dos 15 índices inicialmente considerados. Os 3 fatores, explicativos de quase $89 \%$ das variações dos indicadores que participam da análise, são os seguintes: (i) fator 1 - Controle das Despesas Operacionais, incorporando Índice Combinado, Índice de Despesas Administrativas e Índice de Lucratividade sobre Prêmio Ganho; (ii) fator 2 - Alavancagem, reunindo os índices de Captações, de Endividamento e de Alavancagem Líquida, bem como os Prêmios Retidos sobre Patrimônio Líquido; e (iii) fator 3 - Liquidez, abrangendo os índices de Liquidez Geral e de Liquidez Corrente.

Com o propósito de identificar os índices financeiros de maior significância para explicar o desempenho financeiro de empresas do setor alimentício listadas na Bolsa de Valores de São Paulo, Backes et al. (2009) aplicam a análise fatorial a dados relativos a 2004 e 2006 extraídos das demonstrações financeiras de 21 e 22 empresas, respectivamente. Inicialmente, foram considerados 15 índices financeiros, a saber: liquidez corrente, liquidez seca, liquidez geral, rotação do contas a receber (prazo médio de recebimento), rotação de estoques (prazo médio de estoques), margem líquida (retorno ou rentabilidade líquida sobre a venda), rentabilidade do ativo (ou retorno sobre o ativo), rentabilidade sobre o patrimônio líquido (ou retorno sobre o patrimônio líquido), retorno sobre o investimento, grau de endividamento, quociente de capital de terceiros sobre o capital próprio, quociente de imobilização do patrimônio líquido, grau de alavancagem operacional, grau de alavancagem financeira e giro total do ativo sobre o resultado líquido. Posteriormente, a fim de reduzir o número de variáveis (índices) em função do reduzido número de observações (empresas), foram excluídas as variáveis liquidez seca, rotação de contas a receber, rotação de estoques, quociente de capital de terceiros sobre o capital próprio, quociente de imobilização e giro total do ativo. Considerando os dados relativos a 2004, os autores concluíram que 4 fatores são capazes de explicar $74 \%$ da variabilidade do conjunto de índices: (i) fator 1 - Retorno Sobre o Ativo; (ii) fator 2 - Rentabilidade Sobre as Vendas; (iii) fator 3 - Liquidez; e (iv) fator 4 - Grau de Alavancagem Financeira. A utilização dos dados referentes a 2006 resultou em 3 fatores (que explicam 59\% das variações em tal ano): (i) fator 1 - Rentabilidade; (ii) fator 2 - Retorno sobre Investimento; e (iii) fator 3 - Retorno sobre Patrimônio Líquido.

Em sua pesquisa destinada à proposição de metodologia de seleção dos indicadores financeiros aplicáveis à análise da performance de empresas seguradoras, de modo a reduzir o grau de subjetividade na sua escolha, Silva (2009) aplicou os procedimentos de análise fatorial a dados referentes a 14 variáveis e índices financeiros representativos de 37 daquelas empresas: Lucro por Ação, Valor patrimonial por ação, Margem Bruta, Margem Líquida, Índice de Retorno sobre o Patrimônio Líquido, Rentabilidade do Ativo, Liquidez Geral, Relação Patrimônio Líquido / Ativo Total, Endividamento, Recursos Próprios em Giro, Índice de Imobilização de Recursos, Relação Exigível / Ativo Total, Relação Exigível/Patrimônio Líquido e Relação Ativos Fixos/Patrimônio Líquido. Como resultado, foram obtidos 3 fatores, incorporando 12 das variáveis e índices financeiros inicialmente considerados (retirados os múltiplos Lucro por Ação e Valor patrimonial por ação). Tais fatores, explicativos de $77,7 \%$ das variações dos indicadores utilizados na análise, são os seguintes: (i) fator 1 - 
Rentabilidade dos Recursos Próprios, sendo composto pela Relação Ativo Fixo / Patrimônio Líquido, pela Margem Bruta, pela Margem Líquida e pela Rentabilidade do Ativo; (ii) fator 2 - Endividamento, reunindo o índice de Endividamento, a Relação Exigível / Ativo Total e a Relação Exigível/Patrimônio Líquido de Alavancagem Líquida; e (iii) fator 3 - Liquidez e Giro, abrangendo os índices de Liquidez Geral e de Recursos Próprios em Giro.

Pereira et al. (2006) realizam uso da análise fatorial para identificar os indicadores que melhor explicam o desempenho financeiro de empresas com atuação na distribuição de energia elétrica no Brasil. O estudo realizado utiliza-se dos dados referentes a uma amostra de 40 empresas, obtidos por meio de levantamento das demonstrações contábeis de 2003. Inicialmente foram calculados 19 indicadores financeiros para cada uma das empresas. A análise realizada resultou em 4 fatores, os quais explicam aproximadamente $92 \%$ da associação total entre os dados. O fator 1 é composto pelo índice de Endividamento, pelo nível de Alavancagem Financeira e pelo Grau de Imobilização do Patrimônio Líquido. O fator 2, por sua vez, abrange os indicadores de solvência geral e de garantia de terceiros, representando a situação financeira das empresas perante os capitais de terceiros. O fator 3 é integrado pelos índices de Liquidez Geral, de Liquidez Corrente e Liquidez Seca, enquanto o fator 4 tem em sua composição as variáveis Necessidade de Capital de Giro e Saldo de Tesouraria.

Cabe aqui, por último, destacar o trabalho de Ezzamel et al. (1987), no qual a análise fatorial foi empregada na identificação de padrões de performance financeira em empresas industriais em operação no Reino Unido. Partindo de um conjunto inicial de 152 índices extraíveis de demonstrações contábeis, os autores realizaram a análise fatorial com dados relativos a 53 desses índices, referentes aos anos 1973, 1977 e 1981, obtendo 10 fatores representativos do desempenho financeiro das empresas consideradas. Entre tais fatores, um corresponde à "intensividade" de capital, dois representam diferentes medidas de liquidez, dois fatores estão relacionados à rotatividade de ativos, dois outros fatores estão relacionados à rentabilidade, um fator representa 0 endividamento de longo prazo, um fator corresponde ao capital de giro e, finalmente, um último fator está associado ao nível de estoques das empresas. Tais fatores são referentes, na visão dos autores, a cinco áreas específicas do desempenho financeiro das empresas, a saber, estrutura patrimonial ("intensividade" de capital), rentabilidade, capital de giro (aí incluído o fator associado ao nível de estoques das empresas), liquidez e rotatividade de ativos. Destacam os autores o fato de que fatores relacionados a liquidez, endividamento e rentabilidade podem ser observados em todos os trabalhos por eles mencionados na revisão de literatura.

Os trabalhos mencionados nesta seção constituem, por meio de seus resultados, importantes referências para a presente pesquisa, oferecendo parâmetros para a comparação dos resultados aqui obtidos e, por consequência, para a validação e/ou questionamento das conclusões decorrentes desses resultados.

\section{Metodologia}

O método de pesquisa empregado neste trabalho é dedutivo, que é definido por Lakatos e Marconi (2005) como àquele que busca por soluções parte de teorias ou leis previamente aceitas. Esta pesquisa fará uso do método estatístico e pode ser considerada como sendo uma pesquisa quantitativa exploratória. Quantitativa porque os atributos das variáveis tratadas nesse trabalho são numéricos e serão tratadas como tais. Exploratória porque pretende aumentar o conhecimento existente sobre a utilização de ferramentas de análise estatística multivariada na avaliação de desempenho de empresas atuantes no setor de tecnologia da informação (TI) no Brasil.

O trabalho é desenvolvido com o auxílio do Software SPSS Versão 17.0, com base em dados, relativos aos anos 2007 e 2009, concernentes às duzentas maiores empresas brasileiras do setor de tecnologia de informação. Os dados considerados, disponibilizados pela revista INFOEXAME (relatório INFO200), são representativos das seguintes variáveis e índices financeiros: (i) Vendas; (ii) Patrimônio Líquido; (iii) EBTIDA; (iv) relação EBTIDA / Vendas; (v) Imposto sobre Vendas; (vi) Liquidez Corrente; (vii) Endividamento Financeiro; e (viii) Lucro Líquido. Inicialmente, são calculados os valores referentes a essas oito medidas de desempenho financeiro para cada uma das empresas da amostra considerada, sendo cabível aqui ressaltar que foram excluídas aquelas empresas para as quais não houve a disponibilidade de informações relativas a todas as medidas. Tal procedimento implica que a análise referente ao ano 2007 contemple 144 empresas, enquanto no ano 2009 somente 88 empresas tenham seus considerados para fins de análise. Esses dados, portanto, são submetidos à análise fatorial para determinação de grupos de indicadores (fatores).

O modelo de análise fatorial estima os fatores e as variâncias, de modo que as covariâncias ou as correlações previstas estejam o mais próximo possível dos valores observados. Como exposto anteriormente, os métodos de estimação ou extração mais usados são baseados na análise de componentes principais e na análise fatorial comum. Neste trabalho será usado o método das componentes principais. Inicialmente, verifica-se a adequação 
do emprego da análise fatorial, sendo necessária a existência de correlação entre as variáveis. Se as correlações forem pequenas é pouco provável que estas variáveis partilhem fatores comuns. É assumido como aceitável um valor de correlação acima de 0,4 . No contexto do emprego da análise fatorial, são realizados os testes KMO (Kaiser-Meyer-Olkin) e o de esfericidade de Bartlett.

$\mathrm{O}$ teste $\mathrm{KMO}$, cujos resultados variam entre 0 e 1, testa a adequação da amostra quanto ao grau de correlação parcial entre as variáveis, o qual deve ser reduzido. Um valor para o KMO próximo de 1 indica que os coeficientes de correlação parciais são pequenos, enquanto valores próximos de zero indicam que a análise fatorial pode não ser adequada. No presente estudo, valores inferiores a 0,5 são indicação da inadequação da análise fatorial. $\mathrm{O}$ teste de Bartlett verifica a existência de correlação suficientemente forte para que a Análise Fatorial seja aplicada, testando-se a partir dele as seguintes hipóteses: $\mathrm{H}_{0}$ : Não há um nível de correlação entre as variáveis suficientes para a utilização da Análise Fatorial. A matriz de correlação é uma matriz identidade. A análise fatorial, portanto, não é adequada a esse caso; e $\mathrm{H}_{1}$ : Existe correlação. A utilização da Análise Fatorial é adequada.

Uma vez obtido um valor inferior a 5\% (para um nível de significância estabelecido em 5\%), deve-se rejeitar $\mathrm{H}_{0}$, ou seja, a hipótese de que a matriz das correlações entre as variáveis seja identidade, evidenciando, dessa forma, a existência de correlação entre as variáveis. Em caso contrário, deve-se reconsiderar a utilização da análise fatorial. A Matriz de Correlação Anti-Imagem apresenta correlações parciais, as quais correspondem às correlações entre variáveis quando os efeitos das outras variáveis são considerados, sinalizando, também, a adequação ou não da análise fatorial para indicação de existência de fatores. Nessa matriz, pequenos valores na diagonal levam a considerar a eliminação da variável.

As medidas da adequação da amostra (MSA) constituem outro caminho para a verificação da adequação ou inadequação do emprego da análise fatorial. Tais medidas correspondem aos valores da diagonal principal da matriz, sendo que, quanto maiores eles são, mais adequada é a análise fatorial. Ademais, os valores fora da diagonal representam o simétrico da matriz de correlações, devendo ser reduzidos para a aplicação do modelo das componentes principais. A comunalidade representa a proporção de variância de cada variável explicada pelas componentes principais retidas. De acordo com Hair et al. (2009), o valor mínimo aceitável para as comunalidades é 0,5 .

O número de fatores retidos no processo de análise por fatores pode ser determinado pelo critério de Kaiser, em função do número de valores próprios maiores que 1. Segundo Belfore, Fávero e Ângelo (2006), no método de extração de componentes principais, a soma dos valores próprios iguala ao número de variáveis.

A matriz de componente antes da rotação indica as variáveis que integram cada fator, constituindo, entretanto, uma solução não rotacionada. A matriz componente, após realizada a rotação dos fatores, informa quais variáveis compõem cada fator. Os valores dispostos na matriz representam as cargas fatoriais, isto é, a correlação de cada variável com cada fator. Integram um determinado fator as cargas com maior valor absoluto em módulo.

\section{Resultados}

\subsection{Dados de 2007 - Aanálise com 8 variáveis}

É apresentada a matriz de correlação (Tabela 2) entre as variáveis com o propósito de avaliar a adequação da análise fatorial. Se tais correlações forem pequenas é pouco provável que estas variáveis partilhem fatores comuns. Nesse sentido, é assumido como aceitável um valor de correlação acima de 0,3 (HAIR, 2009).

Tabela 2: Matriz de Correlação

\begin{tabular}{|c|c|c|c|c|c|c|c|c|c|}
\hline & & Vendas & $\mathrm{PL}$ & EBTIDA & EBTID/Vds & Trib/Vds & LiqCorr & EndivFin & LL \\
\hline \multirow[t]{8}{*}{ Correlation } & Vendas & 1,000 & 0,969 & 0,972 & 0,302 & 0,989 & $-0,182$ & $-0,002$ & 0,756 \\
\hline & $\mathrm{PL}$ & 0,969 & 1,000 & 0,944 & 0,324 & 0,956 & $-0,169$ & $-0,036$ & 0,741 \\
\hline & EBTIDA & 0,972 & 0,944 & 1,000 & 0,360 & 0,983 & $-0,163$ & $-0,011$ & 0,870 \\
\hline & EBTID/Vds & 0,302 & 0,324 & 0,360 & 1,000 & 0,307 & 0,145 & $-0,113$ & 0,367 \\
\hline & Trib/Vds & 0,989 & 0,956 & 0,983 & 0,307 & 1,000 & $-0,167$ & $-0,006$ & 0,807 \\
\hline & LiqCorr & $-0,182$ & $-0,169$ & $-0,163$ & 0,145 & $-0,167$ & 1,000 & $-0,368$ & $-0,109$ \\
\hline & EndivFin & $-0,002$ & $-0,036$ & $-0,011$ & $-0,113$ & $-0,006$ & $-0,368$ & 1,000 & $-0,041$ \\
\hline & LL & 0,756 & 0,741 & 0,870 & 0,367 & 0,807 & $-0,109$ & $-0,041$ & 1,000 \\
\hline \multirow[t]{8}{*}{ Sig. (1-tailed) } & Vendas & & 0,000 & 0,000 & 0,002 & 0,000 & 0,045 & 0,493 & 0,000 \\
\hline & $\mathrm{PL}$ & 0,000 & & 0,000 & 0,001 & 0,000 & 0,057 & 0,371 & 0,000 \\
\hline & EBTIDA & 0,000 & 0,000 & & 0,000 & 0,000 & 0,065 & 0,459 & 0,000 \\
\hline & EBTID/Vds & 0,002 & 0,001 & 0,000 & & 0,002 & 0,089 & 0,148 & 0,000 \\
\hline & Trib/Vds & 0,000 & 0,000 & 0,000 & 0,002 & & 0,060 & 0,477 & 0,000 \\
\hline & LiqCorr & 0,045 & 0,057 & 0,065 & 0,089 & 0,060 & & 0,000 & 0,156 \\
\hline & EndivFin & 0,493 & 0,371 & 0,459 & 0,148 & 0,477 & 0,000 & & 0,354 \\
\hline & LL & 0,000 & 0,000 & 0,000 & 0,000 & 0,000 & 0,156 & 0,354 & \\
\hline
\end{tabular}

Fonte: Dados da pesquisa (2015) 
Os valores constantes na matriz de correlação sinalizam para a existência de variáveis fracamente correlacionadas (Liquidez Corrente e Endividamento Financeiro), o que é reiterado na tabela de significância (Sig. 1-Tailed), que mostra essas duas variáveis com reduzida correlação.

Tabela 3: KMO e Teste de Bartlett

\begin{tabular}{l|l|r}
\hline Kaiser-Meyer-Olkin Measure of Sampling Adequacy. & 0,795 \\
\hdashline & Approx. Chi-Square & $1.075,439$ \\
Bartlett's Test of Sphericity & dff & 28 \\
& Sig. & 0,000 \\
\hline
\end{tabular}

Fonte: Dados da pesquisa (2015)

Por outro lado, a realização dos testes KMO (Kaiser-Meyer-Olkin) e o de esfericidade de Bartlett, explicitados na tabela 3, sugerem a adequação do emprego da análise fatorial, pois o teste KMO (Kaiser-Meyer-Olkin) apresenta um resultado de 0,795, superior a 0,5, valor apontado por Malhotra (2001) como mínimo para a adequada realização da análise fatorial, enquanto o teste de Bartlett resulta em valor $(0,000)$ inferior àquele apontado por Bezerra e Corrar (2006) como limite máximo para a análise fatorial $(0,05)$.

Tabela 4: Matriz de Anti-imagem

\begin{tabular}{|c|c|c|c|c|c|c|c|c|c|}
\hline & & Vendas & PL & EBTIDA & EBTID/Vds & Trib/Vds & LiqCorr & EndivFin & LL \\
\hline & PL & $-0,011$ & 0,058 & 0,001 & $-0,024$ & 0,002 & 0,008 & 0,028 & $-0,006$ \\
\hline & EBTIDA & $-0,005$ & 0,001 & 0,011 & $-0,023$ & $-0,003$ & 0,001 & $-0,004$ & $-0,026$ \\
\hline & Trib/Vds & $-0,007$ & 0,002 & $-0,003$ & 0,015 & 0,013 & $-0,010$ & $-0,001$ & $-0,006$ \\
\hline & LiqCorr & 0,007 & 0,008 & 0,001 & $-0,148$ & $-0,010$ & 0,793 & 0,296 & 0,011 \\
\hline & EndivFin & $-0,001$ & 0,028 & $-0,004$ & 0,019 & $-0,001$ & 0,296 & 0,840 & 0,016 \\
\hline & PL & $-0,473$ & ,927(a) & 0,043 & $-0,113$ & 0,090 & 0,036 & 0,127 & $-0,079$ \\
\hline & EBTIDA & $-0,498$ & 0,043 & ,787(a) & $-0,247$ & $-0,239$ & 0,007 & $-0,043$ & $-0,796$ \\
\hline & EBTID/Vds & 0,078 & $-0,113$ & $-0,247$ & ,802(a) & 0,157 & $-0,191$ & 0,024 & 0,061 \\
\hline & Trib/Vds & $-0,627$ & 0,090 & $-0,239$ & 0,157 & ,874(a) & $-0,098$ & $-0,010$ & $-0,171$ \\
\hline & LiqCorr & 0,079 & 0,036 & 0,007 & $-0,191$ & $-0,098$ & ,603(a) & 0,363 & 0,040 \\
\hline & EndivFin & $-0,011$ & 0,127 & $-0,043$ & 0,024 & $-0,010$ & 0,363 & ,496(a) & 0,059 \\
\hline
\end{tabular}

Fonte: Dados da pesquisa (2015)

A tabela 4 reúne os resultados da matriz anti-imagem. Elevados valores na diagonal são indicadores da adequação do uso da análise fatorial. Corrar et al. (2009) explica que valores inferiores a 0,50 são considerados muito pequenos, apontando quais variáveis podem ser excluídas da análise. Apenas a variável Endividamento Financeiro não atende o requisito.

As comunalidades são apresentadas na tabela 5. Sendo expressão da quantidade de variância que uma variável compartilha com todas as outras variáveis incluídas na análise, tem, segundo Hair et al. (2009), 0,5 como valor mínimo aceitável. A observação da referida tabela sugere a exclusão da relação EBTIDA / Vendas da análise fatorial realizada.

Tabela 5: Comunalidades

\begin{tabular}{l|r|r}
\hline & Inicial & \multicolumn{1}{|c}{ Extração } \\
\hline Vendas & 1,000 & 0,951 \\
PL & 1,000 & 0,922 \\
EBTIDA & 1,000 & 0,986 \\
EBTID/Vds & 1,000 & 0,360 \\
Trib/Vds & 1,000 & 0,967 \\
LiqCorr & 1,000 & 0,681 \\
EndivFin & 1,000 & 0,603 \\
LL & 1,000 & 0,755 \\
\hline
\end{tabular}

Método de Extração: Análise das Componentes Principais

Fonte: Dados da pesquisa (2015)

A tabela 6 reúne as informações relativas à variância total explicada. Na coluna "Total", os valores próprios estão em ordem crescente de tamanho, sendo que, na situação inicial, a soma dos valores próprios iguala o número de variáveis, no caso presente, 8 (oito). Dada a existência de dois valores próprios maiores do que 1 , temos que o número de fatores retidos é 2. Em seguida, é realizada a verificação do grau de explicação proporcionado pelos 2 fatores calculados pela análise fatorial. É possível observar que o modelo consegue explicar aproximadamente 
$78 \%$ da variância dos dados originais, que é considerado aceitável.

Tabela 6: Variância Total Explicada

\begin{tabular}{|c|c|c|c|c|c|c|c|c|c|}
\hline \multirow[b]{2}{*}{ Componente } & \multicolumn{3}{|c|}{ Autovalores Iniciais } & \multicolumn{3}{|c|}{ Soma dos Quadrados das Cargas Extraídas } & \multicolumn{3}{|c|}{ Soma dos Quadrados das Cargas Rotadas } \\
\hline & Total & $\%$ of Variance & Cumulative \% & Total & \% of Variance | & Cumulative \% & & \% of Variance & Cumulative \% \\
\hline 1 & 4,779 & 59,739 & 59,739 & 4,779 & 59,739 & 59,739 & 4,779 & 59,739 & 59,739 \\
\hline 2 & 1,447 & 18,088 & 77,827 & 1,447 & 18,088 & 77,827 & 1,447 & 18,088 & 77,827 \\
\hline 3 & 0,809 & 10,113 & 87,939 & & & & & & \\
\hline 4 & 0,585 & 7,307 & 95,246 & & & & & & \\
\hline 5 & 0,319 & 3,991 & 99,238 & & & & & & \\
\hline 6 & 0,046 & 0,575 & 99,812 & & & & & & \\
\hline 7 & 0,009 & 0,116 & 99,929 & & & & & & \\
\hline 8 & 0,006 & 0,071 & 100,000 & & & & & & \\
\hline
\end{tabular}

Fonte: Dados da pesquisa (2015)

A tabela 7 explicita a composição indicada dos fatores estabelecidos, por meio da observação da carga fatorial para cada variável sobre cada fator, ou seja, da medida de correlação de cada variável com o fator. Sugere que o fator 1 seja composto pelas medidas: Vendas, Patrimônio Líquido, EBTIDA, relação Imposto sobre Vendas e Lucro Líquido. O fator 2 incorpora a Liquidez Corrente e o Endividamento Financeiro (em uma relação inversa).

Tabela 7: Matriz de Componentes

\begin{tabular}{l|r|r}
\hline \multirow{2}{*}{ Vendas } & \multicolumn{2}{|c}{ Componente } \\
\cline { 2 - 3 } PL & 0,974 & \multicolumn{1}{c}{2} \\
EBTIDA & 0,960 & $-0,046$ \\
EBTID/Vds & 0,993 & $-0,014$ \\
Trib/Vds & 0,412 & 0,436 \\
LiqCorr & 0,983 & $-0,032$ \\
EndivFin & $-0,184$ & 0,805 \\
LL & $-0,018$ & $-0,776$ \\
\hline Método de Extração: Análise das Componentes Principais & 0,059 \\
\hline
\end{tabular}

a. 2 componentes extraídos.

Fonte: Dados da pesquisa (2015)

A tabela 8 apresenta a matriz de componentes dos fatores após rotação, pelo método Varimax, que representa um tipo de rotação ortogonal, mantendo os fatores perpendiculares entre si, sem correlação entre eles. É o método mais frequentemente usado, minimizando a ocorrência de variáveis com elevadas cargas fatoriais para diferentes fatores, que facilita a identificação de uma dada variável com um único fator, objetivando aumentar o poder explicativo dos fatores.

Tabela 8: Matriz Rotacionada de Componentes

\begin{tabular}{l|r|r}
\hline \multirow{2}{*}{ Vendas } & \multicolumn{2}{|c}{ Component } \\
\cline { 2 - 3 } PL & 0,974 & \multicolumn{1}{|c}{2} \\
EBTIDA & 0,960 & $-0,048$ \\
EBTID/Vds & 0,993 & $-0,015$ \\
Trib/Vds & 0,413 & 0,435 \\
LiqCorr & 0,983 & $-0,034$ \\
EndivFin & $-0,182$ & 0,805 \\
LL & $-0,019$ & $-0,776$ \\
\hline
\end{tabular}

Método de Extração: Análise das Componentes Principais

a. Rotation converged in 3 iterations.

Fonte: Dados da pesquisa (2015)

Os valores constantes da tabela 8 não produz alterações na composição dos fatores estabelecidos. $O$ fator 1 é composto pelas medidas: Vendas, Patrimônio Líquido, EBTIDA, relação Imposto sobre Vendas e Lucro Líquido. E o fator 2 pela Liquidez Corrente e pelo Endividamento Financeiro (em uma relação inversa).

\subsection{Dados de 2007 - análise com 7 variáveis}

Retirada a relação EBTIDA / Vendas, é feita nova análise fatorial, objetivando melhorar a capacidade de explicação do desempenho financeiro das empresas do setor de TI pelos fatores estabelecidos. Os testes de 
Bartlett (nível de significância igual a 0,000) e de KMO (valor igual a 0,792) mantiveram seus resultados praticamente inalterados.

Tabela 9: KMO e Teste de Bartlett - 7 variáveis

\begin{tabular}{l|l|r}
\hline Kaiser-Meyer-Olkin Measure of Sampling Adequacy. & 0,792 \\
\hline \multirow{3}{*}{ Bartlett's Test of Sphericity } & Afpprox. Chi-Square & $1.056,267$ \\
& df & \\
& Sig. & 21 \\
\hline
\end{tabular}

Fonte: Dados da pesquisa (2015)

Tabela 10: Matriz de Anti-imagem - 7 variáveis

\begin{tabular}{|c|c|c|c|c|c|c|c|c|}
\hline & & Vendas & PL & EBTIDA & Trib/Vds & LiqCorr & EndivFin & $\mathrm{LL}$ \\
\hline \multirow[t]{7}{*}{ Anti-image Covariance } & Vendas & ,009 &,- 011 & ,018 &,- 005 &,- 007 & ,008 & $\overline{-, 001}$ \\
\hline & $\mathrm{PL}$ &,- 011 & ,058 &,- 005 &, 000 &, 003 &, 003 & 029 \\
\hline & LL &, 018 &,- 005 & ,093 &,- 027 &,- 006 & ,015 &, 016 \\
\hline & EBTIDA &,- 005 &, 000 &,- 027 &, 012 &,- 003 &,- 004 &,- 004 \\
\hline & Trib/Vds &,- 007 & 003 &,- 006 &,- 003 &, 013 &,- 007 &,- 001 \\
\hline & LiqCorr & 008 & 003 &, 015 &,- 004 &,- 007 & ,823 & ,312 \\
\hline & EndivFin &,- 001 & 029 &, 016 &,- 004 &,- 001 &, 312 & 840 \\
\hline \multirow[t]{7}{*}{ Ānti-image Correlation } & Vendas &, $728^{\mathrm{a}}$ &,- 469 &, 631 &,- 495 &,- 649 & ,096 &,- 012 \\
\hline & $\mathrm{PL}$ &,- 469 &, $929^{\mathrm{a}}$ &,- 073 &, 015 & , 110 & ,015 & ,130 \\
\hline & LL & 631 &,- 073 &, $699^{a}$ &,- 807 &,- 183 & 052 & 058 \\
\hline & EBTIDA &,- 495 & ,015 &,- 807 &, $792^{\mathrm{a}}$ &,- 209 &,- 043 &,- 038 \\
\hline & Trib/Vds &,- 649 &, 110 &,- 183 &,- 209 &, $873^{\mathrm{a}}$ &,- 071 &,- 014 \\
\hline & LiqCorr &, 096 &, 015 & 052 &,- 043 &,- 071 &, $623^{\mathrm{a}}$ &, 375 \\
\hline & EndivFin &,- 012 & , 130 & 058 &,- 038 &,- 014 & ,375 & $461^{\mathrm{a}}$ \\
\hline
\end{tabular}

Fonte: Dados da pesquisa (2015)

A matriz de anti-imagem evidencia, em sua diagonal principal valores superiores a 0,50 , exceto para a variável Endividamento Financeiro. Com base na tabela das comunalidades, é possível observar que todas as variáveis superam o valor mínimo estabelecido $(0,50)$. A variância total explicada sobe para $85,6 \%$, sugerindo um significativo ganho de qualidade dos resultados da análise fatorial. A composição dos fatores permanece inalterada em relação à situação anterior.

Tabela 11: Comunalidades -7 variáveis

\begin{tabular}{l|r|r}
\hline & Inicial & \multicolumn{1}{|c}{ Extração } \\
\hline Vendas & 1,000 & 0,961 \\
PL & 1,000 & 0,929 \\
LL & 1,000 & 0,750 \\
EBTIDA & 1,000 & 0,989 \\
Trib/Vds & 1,000 & 0,977 \\
LiqCorr & 1,000 & 0,683 \\
EndivFin & 1,000 & 0,708 \\
\hline
\end{tabular}

Método de Extração: Análise das Componentes Principais

Fonte: Dados da pesquisa (2015)

Tabela 12: Variância Total Explicada - 7 variáveis

\begin{tabular}{|c|c|c|c|c|c|c|c|c|c|}
\hline \multirow[b]{2}{*}{ Componente } & \multicolumn{3}{|c|}{ Autovalores Iniciais } & \multicolumn{3}{|c|}{ Soma dos Quadrados das Cargas Extraidas } & \multicolumn{3}{|c|}{ Soma dos Quadrados das Cargas Rotadas } \\
\hline & Total & \% of Variance & Cumulative $\%$ & Total & \% of Variance & Cumulative \% & Total & \% of Variance & Cumulative \% \\
\hline 1 & 4,640 & 66,292 & 66,292 & 4,640 & 66,292 & 66,292 & 4,619 & 65,990 & 65,990 \\
\hline 2 & 1,356 & 19,369 & 85,661 & 1,356 & 19,369 & 85,661 & 1,377 & 19,672 & 85,661 \\
\hline 3 & 0,613 & 8,756 & 94,418 & & & & & & \\
\hline 4 & 0,328 & 4,693 & 99,110 & & & & & & \\
\hline 5 & 0,047 & 0,666 & 99,776 & & & & & & \\
\hline 6 & 0,010 & 0,142 & 99,918 & & & & & & \\
\hline 7 & 0,006 & 0,082 & 100,000 & & & & & & \\
\hline
\end{tabular}

Fonte: Dados da pesquisa (2015) 
Tabela 13: Matriz de Componentes - 7 variáveis

\begin{tabular}{l|r|r}
\hline \multirow{2}{*}{ Vendas } & \multicolumn{2}{|c}{ Componente } \\
\cline { 2 - 3 } PL & 0,980 & \multicolumn{1}{c}{2} \\
LL & 0,963 & 0,009 \\
EBTIDA & 0,862 & 0,036 \\
Trib/Vds & 0,994 & 0,076 \\
LiqCorr & 0,988 & 0,032 \\
EndivFin & $-0,209$ & 0,023 \\
\hline Kétodo de Extrac̃ão: Análise das Componentes Principais & $-0,841$ \\
\hline
\end{tabular}

Método de Extração: Análise das Componentes Principais

a. 2 componentes extraídos.

Fonte: Dados da pesquisa (2015)

Tabela 14: Matriz Rotacionada de Componentes -7 variáveis

\begin{tabular}{l|r|r}
\hline \multirow{2}{*}{ Vendas } & \multicolumn{2}{|c}{ Component } \\
\cline { 2 - 3 } PL & 0,978 & \multicolumn{1}{|c}{2} \\
LL & 0,963 & 0,070 \\
EBTIDA & 0,866 & 0,041 \\
Trib/Vds & $-0,007$ \\
LiqCorr & 0,993 & 0,048 \\
EndivFin & $-0,144$ & 0,056 \\
\hline Método de Extração: Análise das Componentes Principais & $-0,814$ \\
\end{tabular}

a. Rotation converged in 3 iterations.

Fonte: Dados da pesquisa (2015)

Nessa situação, a análise fatorial aponta a existência para dois fatores: fator 1 (composto pelas variáveis Vendas, Patrimônio Líquido, EBITDA, relação Impostos / Vendas e Liquidez Corrente), aqui denominado da resultado operacional da empresa; e fator 2 (integrado pelo indicador de Endividamento Financeiro e pelo Lucro Líquido), ilustrativo da estrutura patrimonial e rentabilidade das empresas.

\subsection{Dados de 2009 - análise com 8 variáveis}

A matriz de correlação (tabela 15) entre as variáveis é construída com o propósito de avaliar a adequação da análise fatorial, com base no critério proposto por (Hair et al., 2009), ou seja, é assumido como aceitável um valor de correlação acima de 0,3 .

Tabela 15: Matriz de Correlação

\begin{tabular}{|c|c|c|c|c|c|c|c|c|c|}
\hline & & Vendas & $\mathrm{PL}$ & EBTIDA & EBTID/Vds & Trib/Vds & LiqCorr & EndivFin & LL \\
\hline \multirow[t]{8}{*}{ Correlation } & Vendas & 1,000 & 0,876 & 0,427 & 0,937 & 0,178 & 0,988 & $-0,126$ & 0,087 \\
\hline & PL & 0,876 & 1,000 & 0,686 & 0,849 & 0,192 & 0,880 & $-0,123$ & $-0,012$ \\
\hline & LL & 0,427 & 0,686 & 1,000 & 0,541 & 0,368 & 0,446 & $-0,118$ & 0,016 \\
\hline & EBTIDA & 0,937 & 0,849 & 0,541 & 1,000 & 0,315 & 0,934 & $-0,128$ & 0,090 \\
\hline & EBTD/Vds & 0,178 & 0,192 & 0,368 & 0,315 & 1,000 & 0,171 & $-0,038$ & $-0,025$ \\
\hline & Trib/Vds & 0,988 & 0,880 & 0,446 & 0,934 & 0,171 & 1,000 & $-0,116$ & 0,067 \\
\hline & LiqCorr & $-0,126$ & $-0,123$ & $-0,118$ & $-0,128$ & $-0,038$ & $-0,116$ & 1,000 & $-0,658$ \\
\hline & EndivFin & 0,087 & $-0,012$ & 0,016 & 0,090 & $-0,025$ & 0,067 & $-0,658$ & 1,000 \\
\hline \multirow[t]{8}{*}{ Sig. (1-tailed) } & Vendas & & 0,000 & 0,000 & 0,000 & 0,016 & 0,000 & 0,066 & 0,150 \\
\hline & PL & 0,000 & & 0,000 & 0,000 & 0,011 & 0,000 & 0,072 & 0,441 \\
\hline & LL & 0,000 & 0,000 & & 0,000 & 0,000 & 0,000 & 0,079 & 0,422 \\
\hline & EBTIDA & 0,000 & 0,000 & 0,000 & & 0,000 & 0,000 & 0,063 & 0,141 \\
\hline & EBTD/Vds & 0,016 & 0,011 & 0,000 & 0,000 & & 0,020 & 0,327 & 0,381 \\
\hline & Trib/Vds & 0,000 & 0,000 & 0,000 & 0,000 & 0,020 & & 0,084 & 0,211 \\
\hline & LiqCorr & 0,066 & 0,072 & 0,079 & 0,063 & 0,327 & 0,084 & & 0,000 \\
\hline & EndivFin & 0,150 & 0,441 & 0,422 & 0,141 & 0,381 & 0,211 & 0,000 & \\
\hline
\end{tabular}

Fonte: Dados da pesquisa (2015)

Os valores constantes na matriz de correlação (metade superior da tabela 15) indicam a existência de variáveis fracamente correlacionadas (Liquidez Corrente e Endividamento Financeiro). A tabela de significância (Sig. 1Tailed) informa a predominância de variáveis correlacionadas, com notória exceção das duas variáveis acima referidas.

Os testes KMO (Kaiser-Meyer-Olkin) e o de esfericidade de Bartlett, explicitados na tabela 16, indicam a 
adequação do emprego da análise fatorial, pois o teste KMO (Kaiser-Meyer-Olkin) apresenta um resultado de 0,728 , superior a 0,5 , valor apontado por Malhotra (2001) como mínimo para a adequada realização da análise fatorial, enquanto o teste de Bartlett resulta em valor $(0,000)$ inferior àquele apontado por Bezerra e Corrar (2006) como limite máximo para a análise fatorial $(0,05)$.

Tabela 16: KMO e Teste de Bartlett

\begin{tabular}{l|l|r}
\hline Kaiser-Meyer-Olkin Measure of Sampling Adequacy. & 0,728 \\
\hdashline & Approx. Chi-Square & $1.336,910$ \\
Bartlett's Test of Sphericity & df & 28 \\
& Sig. & 0,000 \\
\hline
\end{tabular}

Fonte: Dados da pesquisa (2015)

Tabela 17: Matriz de Anti-imagem

\begin{tabular}{|c|c|c|c|c|c|c|c|c|c|}
\hline \multirow[t]{6}{*}{ Anti-image Covariance } & Vendas & ,018 &,- 014 & ,027 &,- 013 &,- 006 &,- 016 &,- 004 &,- 016 \\
\hline & PL &,- 014 &, 094 &,- 120 &, 015 &, 050 &,- 003 &, 038 &, 063 \\
\hline & EBTIDA &,- 013 &, 015 &,- 053 &, 083 &,- 075 &,- 006 &,- 004 &,- 007 \\
\hline & EBTD/Vds &,- 006 & 050 &,- 117 &,- 075 & ,721 &, 016 &, 043 & 077 \\
\hline & Trib/Vds &,- 016 &,- 003 &,- 004 &,- 006 &, 016 & ,022 &, 000 &, 009 \\
\hline & EndivFin &,- 016 & ,063 &,- 062 &,- 007 & ,077 & ,009 & ,349 &, 506 \\
\hline \multirow[t]{5}{*}{ Anti-image Correlation } & Vendas & ,728 &,- 330 & 378 &,- 331 &,- 054 &,- 822 &,- 045 &,- 163 \\
\hline & $\mathrm{PL}$ &,- 330 &, $770^{\mathrm{a}}$ &,- 735 & 170 &, 190 &,- 063 & 170 & 291 \\
\hline & LL & ,378 &,- 735 &, $589^{\mathrm{a}}$ &,- 348 &,- 259 &,- 045 &,- 053 &,- 163 \\
\hline & EBTIDA &,- 331 & ,170 &,- 348 &, $885^{\mathrm{a}}$ &,- 308 &,- 141 &,- 019 &,- 032 \\
\hline & EBTD/Vds &,- 054 &, 190 &,- 259 &,- 308 &, $584^{\mathrm{a}}$ & 127 & ,068 & ,128 \\
\hline
\end{tabular}

Fonte: Dados da pesquisa (2015)

A tabela 17 sintetiza os resultados da matriz anti-imagem. Segundo Corrar et al (2009), valores inferiores a 0,50 são muito pequenos para análise, apontando quais variáveis excluir da análise. Observa-se que somente a variável Endividamento Financeiro não atende o requisito mencionado. As comunalidades são apresentadas na tabela 18, observando-se que todas as variáveis satisfazem o valor proposto por Hair et al. (2009), de valor mínimo aceitável, 0,5.

Tabela 18: Comunalidades

\begin{tabular}{l|r|r}
\hline & Inicial & \multicolumn{2}{|c}{ Extração } \\
\hline Vendas & 1,000 & 0,959 \\
PL & 1,000 & 0,902 \\
LL & 1,000 & 0,645 \\
EBTIDA & 1,000 & 0,923 \\
EBTD/Vds & 1,000 & 0,841 \\
Trib/Vds & 1,000 & 0,962 \\
LiqCorr & 1,000 & 0,829 \\
EndivFin & 1,000 & 0,837 \\
\hline Método de Extração: Análise das Componentes Principais
\end{tabular}

Fonte: Dados da pesquisa (2015)

A tabela 19 refere-se à Variância Total Explicada. Na coluna "Total", os valores próprios estão em ordem crescente de tamanho, sendo que, na situação inicial, a soma dos valores próprios iguala o número de variáveis, no caso presente, 8 (oito). Dada a existência de três valores próprios maiores do que 1 , temos que o número de fatores retidos é 3. Apesar das restrições à utilização da variável Endividamento Financeiro, a análise fatorial com todas as variáveis consegue explicar $86,2 \%$ da variância dos dados originais, é considerado aceitável.

A tabela 20, Matriz Componente (Component Matrix), sugere que o fator 1 seja composto pelas seguintes variáveis: Vendas, Patrimônio Líquido, EBTIDA, Lucro Líquido e Impostos sobre Vendas. O fator 2, por sua vez, é composto pela Liquidez Corrente e pelo Endividamento Financeiro (em uma relação inversa), enquanto a relação EBTIDA/Vendas integra o fator 3. 
Tabela 19: Variância Total Explicada

\begin{tabular}{|c|c|c|c|c|c|c|c|c|c|}
\hline \multirow[b]{2}{*}{ Componente } & \multicolumn{3}{|c|}{ Autovalores Iniciais } & \multicolumn{3}{|c|}{ Soma dos Quadrados das Cargas Extraídas } & \multicolumn{3}{|c|}{ Soma dos Quadrados das Cargas Rotadas } \\
\hline & Total & $\%$ of Variance & Cumulative \% & Total & $\%$ of Variance & Cumulative \% & Total & $\%$ of Variance & Cumulative \% \\
\hline 1 & 4,208 & 52,596 & 52,596 & 4,208 & 52,596 & 52,596 & 3,879 & 48,492 & $\overline{48,492}$ \\
\hline 2 & 1,633 & 20,414 & 73,010 & 1,633 & 20,414 & 73,010 & 1,666 & 20,821 & 69,313 \\
\hline 3 & 1,056 & 13,199 & 86,209 & 1 & 13 & 86 & 1 & 17 & 86 \\
\hline 4 & 0,613 & 7,664 & 93,873 & & & & & & \\
\hline 5 & 0,339 & 4,232 & 98,105 & & & & & & \\
\hline 6 & 0,097 & 1,213 & 99,319 & & & & & & \\
\hline 7 & 0,044 & 0,547 & 99,865 & & & & & & \\
\hline 8 & 0,011 & 0,135 & 100,000 & & & & & & \\
\hline
\end{tabular}

Fonte: Dados da pesquisa (2015)

Tabela 20: Matriz de Componentes

\begin{tabular}{l|r|r|r}
\hline \multirow{2}{*}{ Vendas } & \multicolumn{3}{|c}{ Component } \\
\cline { 2 - 4 } PL & 1 & 2 & \multicolumn{1}{c}{3} \\
LL &, 947 &, 032 &,- 245 \\
EBTIDA &, 942 &, 099 &,- 075 \\
EBTD/Vds &, 667 &, 058 &, 443 \\
Trib/Vds &, 958 &, 037 &,- 062 \\
LiqCorr &, 331 &, 088 &, 850 \\
EndivFin &, 949 &, 049 &,- 244 \\
\hline Método de Extração: Análise das Componentes Principais &,, 197 &,- 885 &,- 086 \\
a. 3 componentes extraídos. &, 110 &,- 908 &,- 005 \\
\hline
\end{tabular}

Fonte: Dados da pesquisa (2015)

Em seguida, é apresentada a matriz de componentes dos fatores após rotação, feita pelo método Varimax (combinada com a Normalização Kaiser). Os valores constantes da tabela 21, Matriz Rotacionada de Componentes, não produz alterações na composição dos fatores estabelecidos. O fator 1 (resultado operacional) é composto pelas seguintes medidas: Vendas, Patrimônio Líquido, EBTIDA e relação Imposto sobre Vendas. O fator 2 (estrutura patrimonial) mantém inalterada sua composição, ou seja, Endividamento Financeiro e Liquidez Corrente, enquanto o Lucro Líquido junta-se ao quociente EBITDA / Vendas na composição do fator 3 (rentabilidade).

Tabela 21: Matriz Rotacionada de Componentes Rotated Component Matrix(a)

\begin{tabular}{l|r|r|r}
\hline \multirow{2}{*}{ Vendas } & \multicolumn{3}{|c}{ Component } \\
\cline { 2 - 4 } PL & 1 & 2 & \multicolumn{1}{c}{3} \\
LL &, 975 &, 065 &, 058 \\
EBTIDA &, 923 &, 006 &, 224 \\
EBTD/Vds &, 498 &, 041 &, 628 \\
Trib/Vds &, 929 &, 070 &, 236 \\
LiqCorr &, 057 &,- 007 &, 915 \\
EndivFin &, 978 &, 048 &, 061 \\
\hline Extraction Method: Principal Compon &,- 076 &,- 905 &,- 067 \\
&, 020 &, 913 &,- 047 \\
\hline
\end{tabular}

Extraction Method: Principal Component Analysis.

Rotation Method: Varimax with Kaiser Normalization.

a. Rotation converged in 4 iterations.

Fonte: Dados da pesquisa (2015)

\subsection{Interpretação dos Resultados}

Os dados obtidos da análise fatorial evidenciam que o desempenho financeiro das empresas brasileiras atuantes no setor de TI é explicado pelas variáveis associadas ao resultado operacional, nos dois períodos considerados (antes e após da crise financeira de 2008), embora que isso seja observado no período anterior à referida crise. As variáveis relacionadas à estrutura patrimonial assumem maior relevância no período posterior a 2008, na medida em que é calculado um fator atribuível a elas. É possível, portanto, observar que a crise financeira de 2008 não produziu significativas alterações na composição do desempenho financeiro das empresas de TI, ainda que a maior relevância da estrutura patrimonial comprove que, diante das restrições existentes no mercado de crédito, tenha tornado o nível de endividamento (medida representativa da estrutura de capital) um diferencial de 
performance para empresas avaliadas.

Tabela 22: Síntese de Estudos Anteriores

\begin{tabular}{l|c|c|c}
\hline \multirow{2}{*}{ Estudo } & \multicolumn{3}{|c}{ Fatores Determinantes do Desempenho Financeiro } \\
\cline { 2 - 4 } & $\mathbf{1}$ & $\mathbf{2}$ & $\mathbf{3}$ \\
\hline \hline Carvalho & Liquidez & Rentabilidade & Estrutura \\
\hline Corrar & Margem & Alavancagem & Liquidez \\
\hline Backes (2004) & Rentab/Ativo & Rentab/Vendas & Liquidez \\
\hline Favato & Margem & Estrutura & Liquidez \\
\hline Pereira & Alavancagem & Estrutura & Liquidez \\
\hline Ezzamel & Estrutura & Rentabilidade & Capital de Giro \\
\hline
\end{tabular}

Fonte: Dados da pesquisa (2015)

No tocante aos resultados de outros estudos, a tabela 22 explicita, de forma ordenada, os três fatores mais explicativos do desempenho financeiro das diferentes empresas analisadas. A despeito das especificidades relativas ao setor empresarial analisado e ao momento da análise, é possível observar que a importância das variáveis referentes à performance operacional apontada no presente estudo está de acordo com os resultados gerados em três dos seis estudos considerados - Bezerra e Corrar (2006), Backes et al. (2009) e Silva (2009). Variáveis relacionadas à estrutura patrimonial das empresas são consideradas relevantes somente em dois estudo - Pereira et al. (2006) e Silva (2009).

Ante o exposto, resta evidente que os resultados aqui obtidos informam o alinhamento dos fatores determinantes do desempenho financeiro de empresas brasileiras de tecnologia de informação com aqueles fatores identificados em outros estudos sobre o tema.

\section{Conclusão}

O emprego de indicadores financeiros constitui alternativa importante para a avaliação do desempenho das organizações empresariais. Ainda que usualmente empregados para fazer comparações entre empresas ou mesmo entre unidades de uma mesma companhia, esses indicadores são utilizados, geralmente, de forma individual e sequencial, não havendo uma avaliação da influência de alguns indicadores sobre os demais. Ademais, diante do grande número de índices financeiros existentes, a identificação daqueles mais relevantes para a avaliação da performance financeira de uma empresa é realizada a partir de critérios subjetivos.

A análise fatorial representa uma metodologia de análise de dados que contribui para a otimização dos esforços (por meio da redução do número de variáveis a serem consideradas) e dos resultados (na medida em parte daquelas variáveis mais significantes) associados à avaliação do desempenho financeiro de empresas.

O presente artigo, através da revisão da literatura disponível e do emprego dessa técnica de análise, contribuiu na sua disseminação, oferecendo, uma visão do desempenho financeiro das maiores empresas brasileiras do setor de tecnologia de informação. O tema e o método relacionados a este trabalho comportam estudos posteriores que aprofundem pontos aqui tratados.

\section{Referências}

ASSAF, A. Finanças corporativas e valor. São Paulo: Atlas, 2003;

ASSAF, A.; LIMA, F. G. Curso de administração financeira. São Paulo: Atlas, 2009.

BELFIORE, P. P.; FÁVERO, L. P. L.; DE ANGELO, C. F. Aplicação de técnicas estatísticas multivariadas em empresas de operação logística no Brasil em função de indicadores econômico-financeiros. Revista Eletrônica de Administração - READ, Porto Alegre, Edição 51, Vol. 12, N 3, mai-jun 2006.

BEZERRA, F. A.; CORRAR, L. J. Utilização da análise fatorial na identificação dos principais indicadores para a avaliação do desempenho financeiro: uma aplicação nas empresas de seguro. Revista de Contabilidade e Finanças, São Paulo, Ano 18, v.1, n. 42, p. 50-62, set-dez. 2006.

BACKES, N. A.; SILVA, W. V.; ADÃO, W. J.; DEL CORSO, J. M. Indicadores Contábeis mais apropriados para mensurar o desempenho financeiro das empresas listadas na BOVESPA. Estratégia e Negócios, v. 2, n. 1, jan./jun. 2009

CARVALHO, F. L.; BIALOSKORSKI, S. Identificação dos principais indicadores para avaliação de desempenho financeiro de cooperativas agropecuárias. Revista de Economia e Sociologia Rural, v. 45, n. 1, p. 119-138, jan/mar 2007. 
CASA NOVA, S. P. C. Utilização da análise envoltória de dados (DEA) na análise de demonstrações contábeis. 2002. 317 f. Tese (Doutorado em Contabilidade e Controladoria) - Faculdade de Economia, Administração e Contabilidade, Universidade de São Paulo, São Paulo, 2002.

CATELLI, A. Controladoria: uma abordagem da gestão econômica GECON. $2^{\text {a }}$ Ed. São Paulo: Atlas 2001

CORRAR, L. J.; PAULO, E.; DIAS FILHO, J. M. Análise multivariada, São Paulo: Atlas, 2007

CORRAR, L. J. Indicadores de desempenho de empresas de saneamento básico. 1981. Dissertação (Mestrado) - Faculdade de Economia, Administração e Contabilidade da Universidade de São Paulo. São Paulo: FEA-USP.

EZZAMEL, M; BRODIE, J.; MAR-MOLINERO, C. Financial patterns of UK manufacturing companies. Journal of Business Finance \& Accounting, v. 14, n. 4, winter/1987.

SILVA, V. F. Performance de indicadores financeiros de seguradoras no Brasil: uma análise de componentes principais. In: $9^{\circ}$ Congresso de Contabilidade e Controladoria - FIPECAFI/USP. 18, Anais...São Paulo, 2009.

GIL, A. C. Como elaborar projetos de pesquisa. São Paulo: Atlas, 2002.

GITMAN, L. J. Princípios de Administração Financeira Essencial. Porto alegre: Bookman,2004.

HAIR, J. F. Jr.; ANDERSON, R. E.; TATHAN, R. L.; BLACK, W. C. Análise Multivariada de dados. $6^{\mathrm{a}}$ ed. Porto Alegre: Bookman, 2009.

IBGE. O Setor de Tecnologia da Informação e Comunicação no Brasil 2003-2006. Rio de Janeiro: IBGE, 2009.

IUDÍCIBUS, S.; MARTINS, E.; GELBCKE, R. E. Manual de contabilidade das sociedades por ações. $4^{\mathrm{a}}$ ed. São Paulo: Atlas, 1995.

LAKATOS, E. M.; MARCONI, M. A. Fundamentos de metodologia científica. $6^{\text {a }}$ ed. São Paulo: Atlas, 2005.

LAITINEN, E. Financial Rating of European Technology Companies: an International Comparison. Journal of Business Finance \& Accounting, v. 29, n. 7/8, Sept./Oct. 2002.

KASSAI, J. R; KASSAI, S.; SANTOS, A.; ASSAF, A. Retorno de investimento: abordagem matemática e contábil do lucro empresarial. $2^{a}$ ed. São Paulo: Atlas, 2000.

MALHOTRA, N. K. Pesquisa de marketing: uma orientação aplicada. $3^{\text {a }}$ ed, Porto Alegre: Bookman, 2001

MARION, J. C. Contabilidade empresarial. 15 ed. São Paulo: Atlas, 2009.

MATARAZZO, D. C. Análise financeira de balanços: abordagem básica e gerencial. $6^{\mathrm{a}}$ ed. São Paulo: Atlas, 2003.

PEREIRA, A. F. A. O; PEDROSA JÚNIOR, C.; RAMOS, E. J. S. Modelo e análise de previsão de desempenho pela metodologia de análise multivariada de dados: um estudo empírico do setor de energia elétrica. In: Anais... IX Congresso Internacional de Custos - Florianópolis, SC, Brasil, 28 a 30 de novembro de 2005.

ROSS, S., WESTERFIELD, R., JAFFE, J. Administração Financeira. São Paulo: McGraw-Hill, 2008. 